\title{
Mechanical Properties and Microstructure of a NiCrFeCoMn High-Entropy Alloy Deformed at High Strain Rates
}

\author{
Bingfeng Wang ${ }^{1,2}$, Xianrui Yao ${ }^{2}$, Chu Wang ${ }^{2}$, Xiaoyong Zhang ${ }^{1, *}$ and Xiaoxia Huang ${ }^{2}$ \\ 1 State Key Laboratory for Powder Metallurgy, Central South University, Changsha 410083, China; \\ wangbingfeng@csu.edu.cn \\ 2 School of Materials Science and Engineering, Central South University, Changsha 410083, China; \\ yaoxianrui@csu.edu.cn (X.Y.); wangchu@csu.edu.cn (C.W.); huangxiaoxiacsu@outlook.com (X.H.) \\ * Correspondence: zhangxiaoyong@csu.edu.cn; Tel.: +86-731-88876244
}

Received: 1 October 2018; Accepted: 17 November 2018; Published: 21 November 2018

\begin{abstract}
The equiatomic $\mathrm{NiCrFeCoMn} \mathrm{high-entropy} \mathrm{alloy} \mathrm{prepared} \mathrm{by} \mathrm{arc} \mathrm{melting} \mathrm{has} \mathrm{a}$ single crystallographic structure. Mechanical properties and microstructure of the $\mathrm{NiCrFeCoMn}$ high-entropy alloy deformed at high strain rates $\left(900 \mathrm{~s}^{-1}\right.$ to $\left.4600 \mathrm{~s}^{-1}\right)$ were investigated. The yield strength of the $\mathrm{NiCrFeCoMn} \mathrm{high-entropy} \mathrm{alloy} \mathrm{is} \mathrm{sensitive} \mathrm{to} \mathrm{the} \mathrm{change} \mathrm{of} \mathrm{high} \mathrm{strain} \mathrm{rates.}$ Serration behaviors were also observed on the flow stress curves of the alloy deformed at the strain rates ranging from $900 \mathrm{~s}^{-1}$ to $4600 \mathrm{~s}^{-1}$. The Zerilli-Armstrong constitutive equation can be used to predict the flow stress curves of the NiCrFeCoMn high-entropy alloy. Large amounts of deformation bands led to obvious serration behaviors of the $\mathrm{NiCrFeCoMn}$ high-entropy alloy under dynamic loading.
\end{abstract}

Keywords: high-entropy alloy; electron microscopy; plasticity methods; plasticity; serration behavior

\section{Introduction}

The concept of multi-component high-entropy alloys (HEAs) has been presented in the beginning of this century. Most HEAs usually contain five elements with nearly equal atomic ratios [1]. HEAs have excellent mechanical properties, such as low strength and high plasticity [2-12]. From recent literatures, the hardness of $\mathrm{FeCoNiCrMn} \mathrm{high-entropy} \mathrm{alloy} \mathrm{has} \mathrm{even} \mathrm{increased} \mathrm{to}$ $6700 \mathrm{MPa}$ [13]. The $\mathrm{Al}_{0.6} \mathrm{CoCrFeNi}$ high-entropy alloy also displayed the excellent strength-ductility combination for nanoscale deformation twins induced by dynamic loading and high-density dislocation substructure [14]. However, the $\mathrm{NiCrFeCoMn} \mathrm{high-entropy} \mathrm{alloy} \mathrm{has} \mathrm{still} \mathrm{been} \mathrm{regarded} \mathrm{as}$ a typical case for its single-phase face-centered cubic (FCC) [15] and relative promising mechanical properties. For example, its yield strength increases with the angle of rotation at high-pressure torsion (HPT) at room temperature at the cost of reduced ductility [16] and can reach up to $350 \mathrm{MPa}$ when reducing its grain size $[17,18]$. Therefore, the $\mathrm{NiCrFeCoMn}$ high-entropy alloy prepared by arc melting can be used to fabricate big parts of industry devices or as the transitional layer between the two types of alloys, e.g., the HEA solder used for welding pure titanium and chromium-nickel-titanium stainless steel [19]. At the present time, dynamic impacts are widely found in aeronautical engineering, the automotive industry, and marine engineering. The as-cast $\mathrm{NiCrFeCoMn}$ high-entropy alloy could be applied to many dynamic deformation processes such as penetration, impact cyclic loading, and shock loading. Hence, it is vital to comprehend the dynamic behavior of as-cast $\mathrm{NiCrFeCoMn}$ high-entropy alloy under low/high-speed loading and expand its applications.

Many researchers were devoted to investigating the deformation behavior of the high-entropy alloy at different strain rate levels $\left(1 \times 10^{-8} \mathrm{~s}^{-1}\right.$ to $\left.10 \mathrm{~s}^{-1}\right)$ [20]. From the recent research, serration 
behavior was found in the high-entropy alloy CoCrFeMnNi prepared by powder metallurgy at a low strain rate of $1 \times 10^{-3} \mathrm{~s}^{-1}$ and the high strain rates $\left(1 \times 10^{3} \mathrm{~s}^{-1}\right.$ to $\left.3 \times 10^{3} \mathrm{~s}^{-1}\right)$ [21]. Serration behavior was supposed to be associated with Cottrell atmosphere interaction with moving dislocations, slip bands, and dynamic strain aging, i.e., the dynamic breakaway/locking of dislocations from/by mobile solute atoms at intermediate temperatures. Until now, only several researches on dynamic behavior of high-entropy alloys under high strain rates (beyond $1 \times 10^{3} \mathrm{~s}^{-1}$ ) have been published. Kumar et al. [22] had investigated the strain-rate sensitivity of yield strength for the $\mathrm{Al}_{0.1} \mathrm{CrFeCoNi}$ high-entropy alloy under high strain rates. Li et al. [23] had also suggested that the $\mathrm{Al}_{0.3} \mathrm{CoCrFeNi}$ high-entropy alloy exhibits high strain-rate sensitivity. Dirras et al. [24] had found that the $\mathrm{Ti}_{20} \mathrm{Hf}_{20} \mathrm{Zr}_{20} \mathrm{Ta}_{20} \mathrm{Nb}_{20}$ high-entropy alloy would be strongly localized under deformation at high strain rates. He et al. [25] had discussed the strain-rate sensitivity effect for the FeCoNiCrMn high-entropy alloy and found a higher strain-rate sensitivity of 0.022 than that of traditional FCC metals. Park et al. [26] had even found that the strain-rate dependency of the yield strength under dynamic conditions would be much higher than that under quasi-static conditions. However, the mechanism of the special phenomenon for the high-entropy alloy deformed at high strain rates (beyond $1 \times 10^{3} \mathrm{~s}^{-1}$ ) is not clear yet. Serration characteristics are ubiquitous in many structural and functional materials such as high-entropy alloy $\left(\mathrm{AlCoCr}_{1.5} \mathrm{Fe}_{1.5} \mathrm{NiTi}_{0.5}, \mathrm{Al}_{0.3} \mathrm{CoCrFeNi}\right.$ etc.). It would lead to the instability of mechanical properties. By studying the serration behavior, it may be possible to have an early warning signal for oncoming epileptic seizures and perhaps economic trends.

In the present work, we used the split-Hopkinson pressure bar to investigate the dynamic mechanical behavior of $\mathrm{NiCrFeCoMn} \mathrm{high-entropy} \mathrm{alloy} \mathrm{prepared} \mathrm{by} \mathrm{arc} \mathrm{melting.} \mathrm{The} \mathrm{aims} \mathrm{are:}$ (1) To report the mechanical properties and microstructure under dynamic loadings, (2) to obtain the plastic model, and (3) to discuss the microstructural mechanism for the serration behavior when the alloy deforms at high strain rates.

\section{Experiments and Procedures}

The material was prepared by arc melting and the chemical composition is given in Table 1 . Figure 1 shows the optical micrograph of the initial microstructure of the sample. The obtained specimen exhibits an as-cast dendrite structure and the columnar crystals are distributed evenly. Elemental scanning results in Figure 2 show the distribution of each element evenly in the alloy. From the XRD pattern shown in Figure 3, it can be found that the NiCrFeCoMn high-entropy alloy is composed of a simple FCC solid solution.

Table 1. Chemical composition of the NiCrFeCoMn high-entropy alloy.

\begin{tabular}{cccccc}
\hline Elements & $\mathbf{C r}$ & $\mathbf{M n}$ & $\mathbf{F e}$ & Co & Ni \\
\hline wt. $\%$ & 16.42 & 18.06 & 21.64 & 21.71 & 22.18 \\
at. $\%$ & 17.76 & 18.49 & 21.79 & 20.72 & 21.24 \\
\hline
\end{tabular}

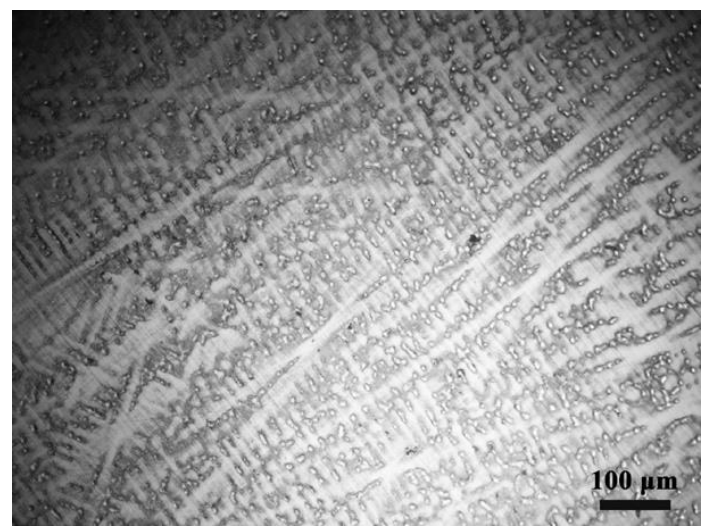

Figure 1. Optical micrograph of the as-cast $\mathrm{NiCrFeCoMn}$ alloy. 

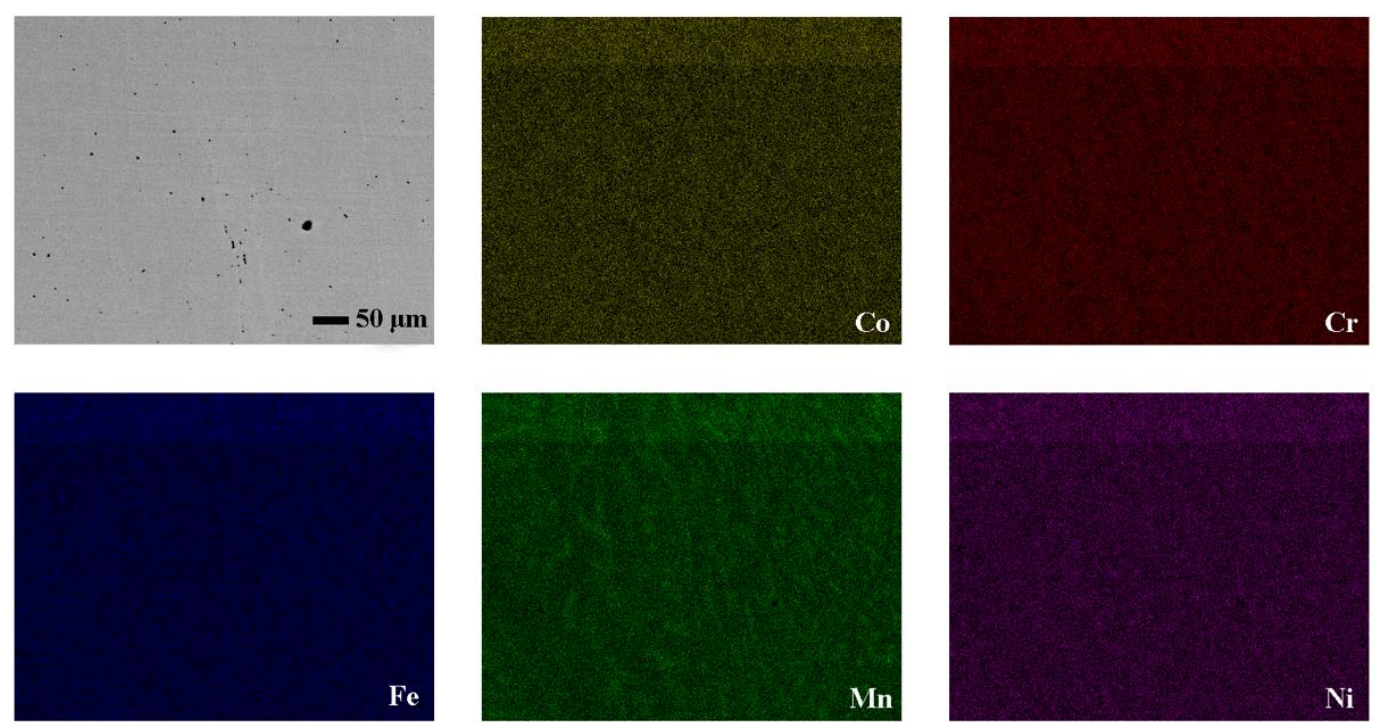

Figure 2. Element planar pattern of the as-cast NiCrFeCoMn alloy.

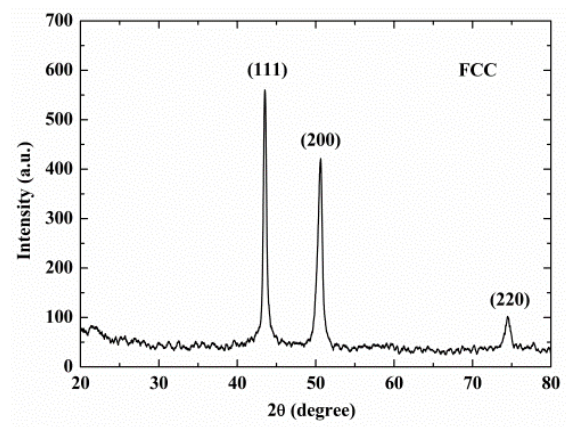

Figure 3. The XRD pattern of the as-cast NiCrFeCoMn alloy.

In this investigation, cylindrical specimens were used for mechanical testing. To ensure uniaxial compressive condition, the end faces of the compressive specimens were ground on each side with $\mathrm{SiC}$ paper. During the process of the impact loading and the electrical signal collection, we had adopted advanced waving plastic and anti-jamming techniques. Two kinds of compressive tests were adopted to do mechanical testing at an ambient temperature (298 K) as follows: (1) Quasi-static compressive tests were performed with an INSTRON 3369 machine at the strain rate of $1 \times 10^{-3} \mathrm{~s}^{-1}$, (2) dynamic compressive tests were performed with a split-Hopkinson pressure bar at the strain rates of $900 \mathrm{~s}^{-1}$, $1700 \mathrm{~s}^{-1}$, and $4600 \mathrm{~s}^{-1}$. The cylindrical specimens had three diameters. Specimens for the strain rate of about $900 \mathrm{~s}^{-1}$ had a height of $8.4 \mathrm{~mm}$ and diameter of $6 \mathrm{~mm}$, for the strain rate of about $1700 \mathrm{~s}^{-1}$ they had a height of $5.6 \mathrm{~mm}$ and diameter of $4 \mathrm{~mm}$, and for the strain rate of about $4600 \mathrm{~s}^{-1}$ they had a height of $2.8 \mathrm{~mm}$ and diameter of $2 \mathrm{~mm}$. The strain rate, the true strain, and the true stress of cylindrical specimens can be obtained by the following equations:

$$
\begin{gathered}
\dot{\varepsilon}=-\frac{2 \mathrm{C}_{0}}{\mathrm{~L}_{\mathrm{S}}} \varepsilon_{r}(t), \\
\varepsilon=-\frac{2 \mathrm{C}_{0}}{\mathrm{~L}_{\mathrm{S}}} \int_{0}^{t} \varepsilon_{r}(t) d t, \\
\varepsilon=-\frac{2 \mathrm{C}_{0}}{\mathrm{~L}_{\mathrm{S}}} \int_{0}^{t} \varepsilon_{r}(t) d t,
\end{gathered}
$$

where $E_{0}$ and $C_{0}$ are elastic modulus and elastic wave speed in a split-Hopkinson pressure bar, $A_{0}$ is the cross-sectional area of the bar, $\mathrm{A}_{\mathrm{s}}$ and $\mathrm{L}_{\mathrm{s}}$ are the cross-sectional area and the length of the cylindrical 
specimens, and $\varepsilon_{r}(t)$ and $\varepsilon_{t}(t)$ are the experimentally measured strain of incident and transmitted stress pulse on the split-Hopkinson pressure bars respectively.

Cylindrical specimens were sectioned to two halves along the impacting axis by line cutting. Afterwards, the half sections were polished with the etchant of $50 \mathrm{~mL}$ hydrochloric acid, $50 \mathrm{~mL}$ water, and $10 \mathrm{~g} \mathrm{CuSO}_{4} \cdot 5 \mathrm{H}_{2} \mathrm{O}$. Samples were cured and ground using $\mathrm{SiC}$ papers. Polishing steps were employed by using diamond pastes and polishing cloths. A mixture solution of $90 \%$ acetic acid and $10 \%$ perchloric acid at room temperature and at an applied voltage of $27 \mathrm{~V}$ for $15 \mathrm{~s}$ was then used for electro-polishing. Optical microscopy was performed with a POLYVAR-MET microscope. The crystallographic structure was identified by X-ray diffraction (Rigaku D/MAX-2500 $\mathrm{X}$-ray diffractometer, Rigaku Corporation, Tokyo, Japan) using a $\mathrm{Cu}$ target at an operating voltage of $40 \mathrm{kV}$ and current of $250 \mathrm{~mA}$. Electron backscatter diffraction (EBSD) patterns were collected using a ZEISS EVOMA10 scanning electron microscope (SEM, Carl Zeiss SMT Ltd., Cambridge, UK) equipped with a detector and operated at an accelerating voltage of $20 \mathrm{kV}$. The working distance for SEM is about $10 \mathrm{~mm}$. Transmission electron microscopy (TEM, Royal Philips, Amsterdam, Netherlands) observations were carried out with a Tecnai G2 T20 ST transmission electron microscope operated at $200 \mathrm{kV}$.

\section{Results}

Figure 4 presents the true stress-strain curves of the NiCrFeCoMn high-entropy alloy. It can be seen that the yield strength of the $\mathrm{NiCrFeCoMn} \mathrm{high-entropy} \mathrm{alloy} \mathrm{increased} \mathrm{from} 490 \mathrm{MPa}$ to $800 \mathrm{MPa}$, with the strain rates varying from $900 \mathrm{~s}^{-1}$ to $4600 \mathrm{~s}^{-1}$. The flow stress curves are likely smoothed when the specimens are deformed at the strain rate of $0.001 \mathrm{~s}^{-1}$ at an ambient temperature ( $298 \mathrm{~K})$. However, the serrations appeared on the flow stress curves of the specimens deformed at high strain rates (e.g., $900 \mathrm{~s}^{-1}, 1700 \mathrm{~s}^{-1}$, and $4600 \mathrm{~s}^{-1}$ ). Furthermore, with the increasing of the strain rates, the serrations on the flow stress curves became more serious.

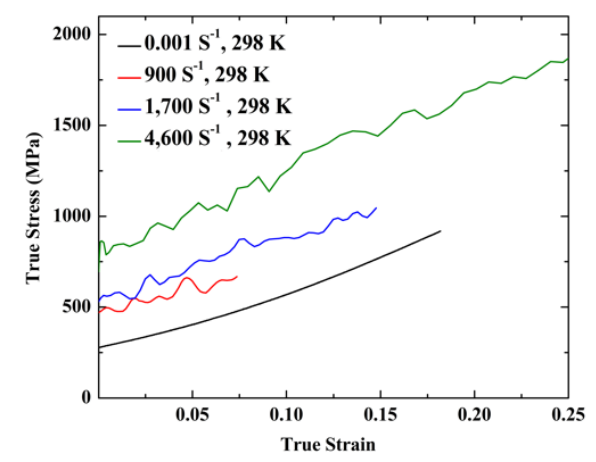

Figure 4. Compressive true stress-strain curves of the NiCrFeCoMn high-entropy alloy at different strain rates.

The EBSD technique was used to investigate the microstructure and the micro-orientation of a $\mathrm{NiCrFeCoMn}$ high-entropy alloy. Figure $5 \mathrm{a}-\mathrm{c}$ are the electron backscattered diffraction images of the as-received specimen, the specimen deformed at the strain rate of $0.001 \mathrm{~s}^{-1}$, and the specimen deformed at the strain rate of $4600 \mathrm{~s}^{-1}$. First, the noise of the images was reduced. Then, to Figure $5 \mathrm{~b}, \mathrm{c}$ were added a layer of full Euler angles after adding a layer of band contrast. The size of the Kuwahara filter was 3-pixel points $\times 3$-pixel points and the smoothing angle was $5^{\circ}$. Among them, high-angle boundaries $\left(60^{\circ}\right)$ were marked with black lines. It is evident that the alloy in the as-cast condition consisted of grains on the order of micrometers in size. A visual comparison of Figure $5 b, c$ suggests a higher density of high-angle boundaries in the specimen deformed at a high strain rate of $4600 \mathrm{~s}^{-1}$ compared to the specimen deformed at a low strain rate of $0.001 \mathrm{~s}^{-1}$. Further, the intensive deformation bands were generated in the specimen deformed at a high strain rate of $4600 \mathrm{~s}^{-1}$, as shown in Figure 5c. Therefore, the obvious serrations in flow stress curves of the specimen deformed at high strain rates are caused by the intensive deformation bands. 


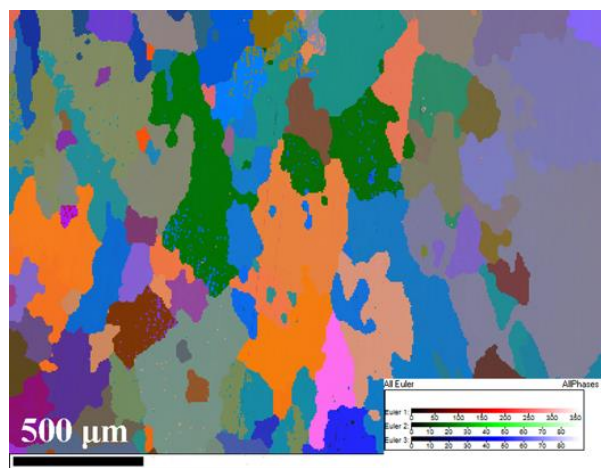

(a)

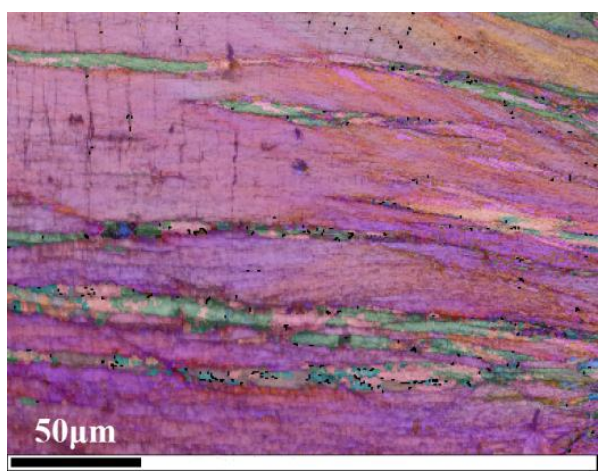

(b)

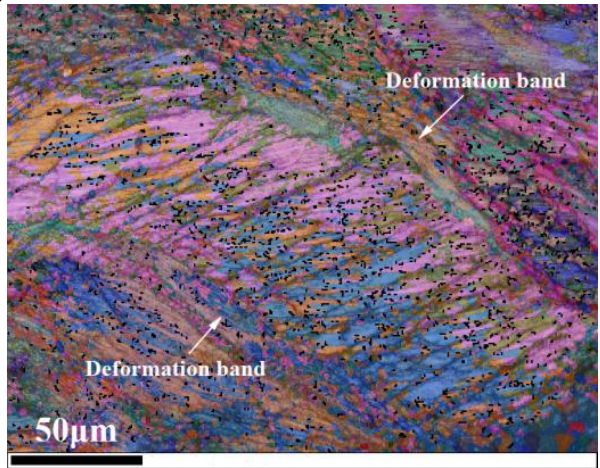

(c)

Figure 5. Electron backscattered diffraction images. (a) the Euler image of the as-received specimen; (b) the Euler+BC image of the deformed specimen at the strain rate $1 \times 10^{-3} \mathrm{~s}^{-1}$; (c) the Euler+BC image of the deformed specimen at the strain rate $4600 \mathrm{~s}^{-1}$.

Bright field electron images taken for the specimens deformed at strain rates of $1700 \mathrm{~s}^{-1}$ and $4600 \mathrm{~s}^{-1}$ are shown in Figure 6. Figure 6a,c show the high-density dislocations and deformation bands that were formed in the $\mathrm{NiCrFeCoMn}$ high-entropy alloy. These deformation bands were distributed in parallel. The deformation band consisted of nanograins, as shown in Figure 6b,d. Comparing Figure $6 a, b$ and Figure $6 c, d$, the parallel deformation bands were more clear when the specimen was deformed at relative lower strain rates as shown in Figure $6 a, c$, and the sizes of the nanograins in the specimens under a strain rate of $1700 \mathrm{~s}^{-1}$ were larger than those in the specimens deformed at a strain rate of $4600 \mathrm{~s}^{-1}$.

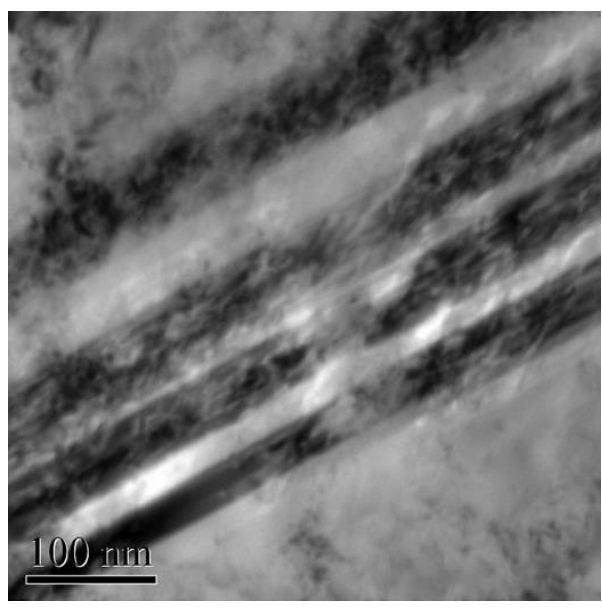

(a)

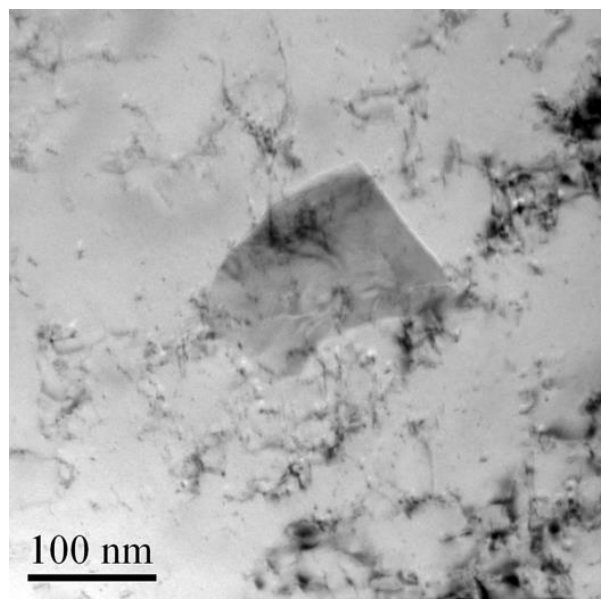

(b)

Figure 6. Cont. 


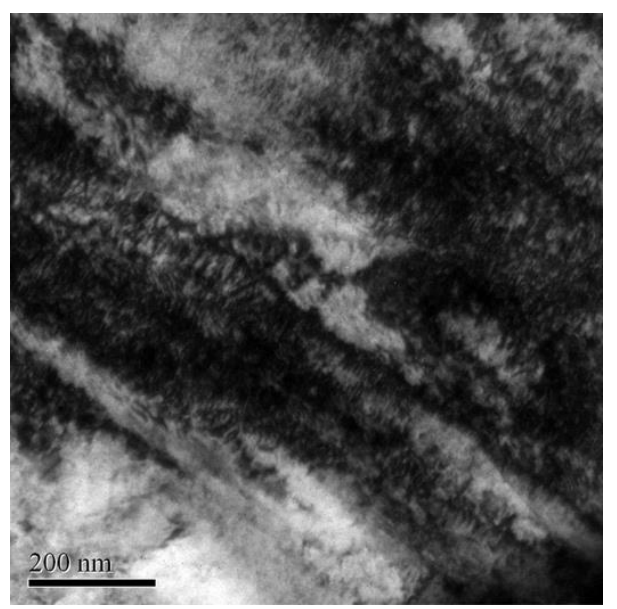

(c)

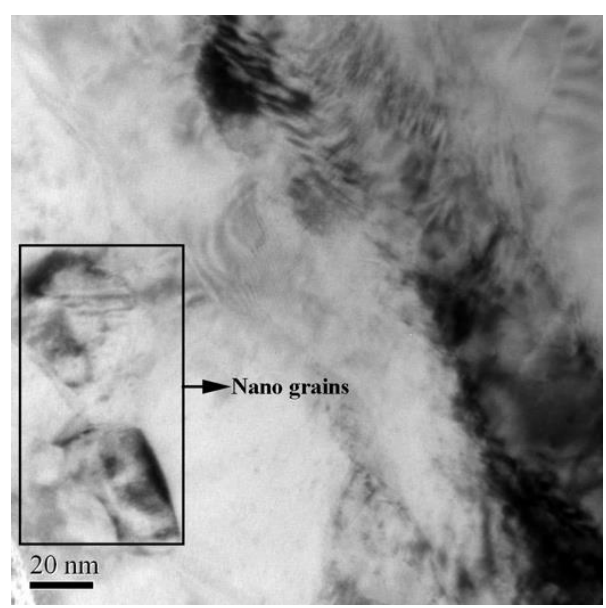

(d)

Figure 6. Bright field electron images showing microstructure in the specimens deformed at high strain rates. (a) and (b) are for the specimen deformed at the strain rate of about $1700 \mathrm{~s}^{-1}$ (c) and (d) are for the specimen deformed at the strain rate of about $4600 \mathrm{~s}^{-1}$.

\section{Discussion}

\subsection{The Constitutive Model and Strain-Rate Sensitivity}

The main dynamic constitutive equations are the Johnson-Cook and Zerilli-Armstrong plastic models. Among them, the Johnson-Cook model is the most widely used for its relative simple expression. It can be represented as follows $[27,28]$ :

$$
\sigma=\left(\mathrm{A}+\mathrm{B} \varepsilon^{n}\right)\left[1+\mathrm{C} \ln \left(\frac{\dot{\varepsilon}}{\dot{\varepsilon_{0}}}\right)\right]\left[1-\left(\frac{T-T_{r}}{T_{m}-T_{r}}\right)^{m}\right],
$$

where $\mathrm{A}, \mathrm{B}$, and $\mathrm{C}$ are material constants, $\sigma$ and $\varepsilon$ are the flow stress and the equivalent plastic strain respectively, $\dot{\varepsilon}$ and $T$ are the equivalent plastic strain rate and the experimental temperature respectively, and $T_{r}$ and $T_{m}$ are the reference temperature (usually room temperature) and the melting point, respectively.

The dislocation mechanism is important for studying the plastic deformation of metallic materials under dynamic deformation. Therefore, the Zerilli-Armstrong plastic model improves the Johnson-Cook model on the basis of dislocation mechanism [29]. In this work, the Zerilli-Armstrong plastic model was used for predicting the strain rate flow behavior of the as-cast $\mathrm{NiCrFeCoMn}$ high-entropy alloy. It can be represented as follows:

$$
\sigma=\mathrm{C}_{0}+\mathrm{C}_{1} \times \varepsilon^{\mathrm{P}} \times \exp \left[-\mathrm{C}_{2} T+\mathrm{C}_{3} T \ln \left(\frac{\dot{\varepsilon}}{\dot{\varepsilon_{0}}}\right)\right],
$$

where $C_{0}, C_{1}, C_{2}, C_{3}$, and $P$ are material constants. Note that $T$ is $298 \mathrm{~K}$.

Taking initial values of the Johnson-Cook model as follows: $\mathrm{A}=1, \mathrm{~B}=4, \mathrm{C}=100, n=1$, then the parameter values and the constitutive relation of stress-strain with strain rate could be obtained by using the MATLAB program (Version 7.0). Therefore, the constitutive equation based on the Johnson-Cook plastic model can be obtained as follows:

$$
\sigma=\left(0.6039+4.81 \varepsilon^{1}\right)\left[1+121.6 \ln \left(\frac{\dot{\varepsilon}}{\dot{\varepsilon_{0}}}\right)\right]
$$


As above, taking initial values of the Zerilli-Armstrong model as follows: $C_{0}=400, C_{1}=9 \times 10^{5}$, $\mathrm{C}_{2}=0.01, \mathrm{C}_{3}=0.001, \mathrm{P}=0.5$, then the constitutive equation based on the Zerilli-Armstrong plastic model can be obtained as follows:

$$
\sigma=473.3+9.3 \times 10^{5} \times \varepsilon^{0.5} \times \exp \left[-0.0415 T+0.0026 T \ln \left(\frac{\dot{\varepsilon}}{\dot{\varepsilon_{0}}}\right)\right] .
$$

Figure 7 shows the comparison of the calculated results obtained from Equations (6) and (7) and the experimental data of the $\mathrm{NiCrFeCoMn}$ high-entropy alloy specimens. It can be seen that the results predicted by the Zerilli-Armstrong plastic model are in better agreement with the experimental results.

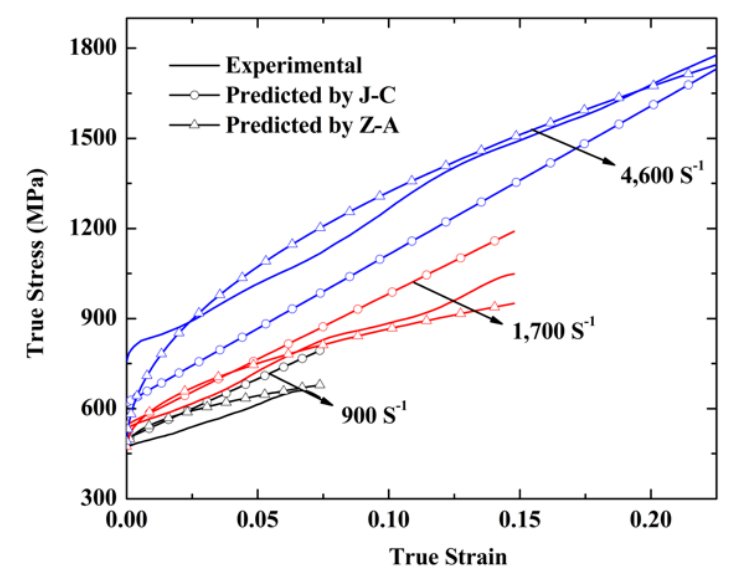

Figure 7. Comparison between the experimental results and the stress calculated by the Johnson-Cook and the Zerilli-Armstrong plastic models at 298K.

Figure 8 shows the yield strength vs. strain rate curves of the as-cast $\mathrm{NiCrFeCoMn} \mathrm{high-entropy}$ alloy as a function of strain rate at ambient temperature. The strain-rate sensitivity is defined as follows:

$$
\mathrm{m}=\frac{d(\log \sigma)}{d(\log \dot{\varepsilon})} .
$$

Notice that the yield strength distributes from $200 \mathrm{MPa}$ to $800 \mathrm{MPa}$ and the slope of the tangent for the curve is increasing with the increase of strain rates. Therefore, the as-cast $\mathrm{NiCrFeCoMn}$ high-entropy alloy has distinguished strain-rate sensitivity at high strain rates.

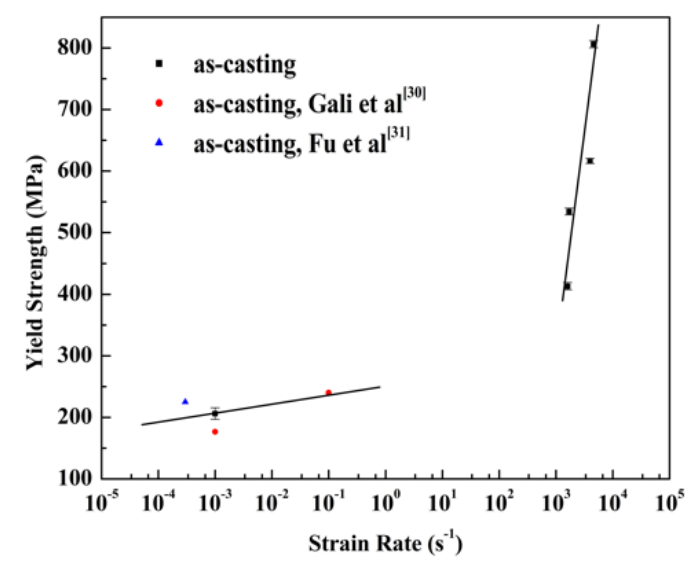

Figure 8. The yield strength vs. strain rate curves of the NiCrFeCoMn high-entropy alloy [30,31].

He et al. [32] studied the stress exponent (the reciprocal of strain rate sensitivity) of the $\mathrm{NiCrFeCoMn} \mathrm{high-entropy} \mathrm{alloy} \mathrm{deformed} \mathrm{under} \mathrm{strain} \mathrm{rates} \mathrm{less} \mathrm{than} 10^{-2} \mathrm{~s}^{-1}$. He found that 
the stress exponent was in a positive relationship with the strain rates. When the strain rate ranged from $3.205 \times 10^{-5}$ to $8.013 \times 10^{-4} \mathrm{~s}^{-1}$, the stress exponent increased simultaneously. Moon et al. [33] also studied the strain rate sensitivity at the elevated temperature and the cryogenic temperature, respectively. The results showed that the flow stress at $77 \mathrm{~K}$ was higher than that at room temperature. Therefore, the strain rate sensitivity of the flow stress at RT was higher than that at $77 \mathrm{~K}$ under strain rates less than $1 \times 10^{-2} \mathrm{~s}^{-1}$. The following formula can explain this phenomenon:

$$
V^{*}=\sqrt{3} \mathrm{k} T \frac{\partial \ln \dot{\varepsilon}}{\partial \sigma}
$$

where $\mathrm{k}$ is the Boltzmann constant and $V^{*}$ is activation volume.

The NiCrFeCoMn high-entropy alloy had positive activation volume at strain rates less than $1 \times 10^{-2} \mathrm{~s}^{-1}$. However, when the specimen deformed under high strain rates (beyond $1 \times 10^{3} \mathrm{~s}^{-1}$ ), the deformation time was very short. There was not enough time available for thermal energy to help dislocations overcome the barriers. The $\mathrm{NiCrFeCoMn} \mathrm{high-entropy} \mathrm{alloy} \mathrm{had} \mathrm{a} \mathrm{different} \mathrm{deformation}$ mechanism at dynamic loading. According to the literature [22], the large jump in yield strength at high strain rates is probably due to the phonon drag effect on the motion of dislocations. The phonon drag phenomenon becomes very effective during plastic deformation at high strain rates [22]. A phonon is an elastic lattice vibration propagating in a crystal [26]. The viscous drag generating from the interaction of the dislocations has negative impacts on the deformation progress. The drag effects by the phonons can be ignored under quasi-static conditions for low dislocation velocities. However, high dislocation velocities under high strain rates would enhance the phonon drag effects greatly and lead to phonons scattering, which also hinders dislocation movement. Therefore, the dynamic deformations lead to a much higher strain rate dependence of the flow stress than those under quasi-static conditions.

\subsection{Mechanism for the Serration Behavior}

High-entropy alloys present serrations on the flow stress curves during the plastic deformation, often at a normal strain rate around $1 \times 10^{-4} \mathrm{~s}^{-1}$ or at low temperatures. Serration behavior exhibits in the stress-strain curves of the $\mathrm{Al}_{0.5} \mathrm{CoCrCuFeNi}$ high-entropy alloy at $7 \mathrm{~K}, 7.5 \mathrm{~K}$, and $9 \mathrm{~K}$ at a strain rate of $4 \times 10^{-4} \mathrm{~s}^{-1}$ [19]. The $\mathrm{Al}_{5} \mathrm{Cr}_{12} \mathrm{Fe}_{35} \mathrm{Mn}_{28} \mathrm{Ni}_{20}$ high-entropy alloy exhibits typical serration behaviors at the elevated temperatures of $573 \mathrm{~K}$ and $673 \mathrm{~K}$, with a strain rate of $1 \times 10^{-4} \mathrm{~s}^{-1}$ [34]. Several microstructure mechanisms are proposed to explain the serration behavior, e.g., the Portevin-Le Chatelier (PLC) effect. Serration behavior was supposed to be associated with Cottrell atmosphere interaction with moving dislocations, slip bands, and dynamic strain aging. In Figure 4, it can be seen that the stress-strain curves of the as-cast $\mathrm{NiCrFeCoMn} \mathrm{high-entropy} \mathrm{alloy} \mathrm{deformed} \mathrm{at} \mathrm{a} \mathrm{strain}$ rate of $1 \times 10^{-3} \mathrm{~s}^{-1}$ show no serrations, and marked serrations are present on the stress-strain curves of specimens deformed at strain rates above $900 \mathrm{~s}^{-1}$. With increasing strain rates, amplitudes of the serrations on the stress-strain curves become much larger. Investigations on the microstructure in the as-cast $\mathrm{NiCrFeCoMn} \mathrm{high-entropy} \mathrm{alloy} \mathrm{show} \mathrm{that} \mathrm{the} \mathrm{high} \mathrm{density} \mathrm{dislocations} \mathrm{and} \mathrm{the}$ deformation bands are generated in the specimens deformed at high strain rates, shown in Figures 5 and 6. The Portevin-Le Chatelier effect, i.e., Cottrell atmosphere interaction with moving a simple dislocation structure, may not be the main reason for the serration behavior of the as-cast $\mathrm{NiCrFeCoMn}$ high-entropy alloy becoming deformed at dynamic loadings. On the other hand, if the dynamic deformation becomes more serious and the value of the strain rate increases, deformation bands are generated in the as-cast $\mathrm{NiCrFeCoMn}$ high-entropy alloy and the amplitudes of the serrations on the stress-strain curves become much larger. Therefore, large amounts of the deformation bands, leading to the serration behaviors, play an important role for the mechanical properties of the high-entropy alloy.

\section{Conclusions}

The as-cast equiatomic NiCrFeCoMn high-entropy alloy has a simple FCC crystallographic structure. Serration behavior is observed in the stress- strain curves of the as-cast $\mathrm{NiCrFeCoMn}$ 
high-entropy alloy deformed at dynamic loadings. The yield strength of the high-entropy alloy, which distributes from 490 to $800 \mathrm{MPa}$, presents a positive relationship with the strain rates. The Johnson-Cook plastic model and the Zerilli-Armstrong plastic model of the NiCrFeCoMn high-entropy alloy are obtained. However, the results predicted by Zerilli-Armstrong correspond better with the experimental results. The serration behavior of the $\mathrm{NiCrFeCoMn}$ high-entropy alloy at a high strain rate is sensitive to the strain rates. The high density of deformation bands plays an important role in the deformation behavior and mechanical properties of the as-cast $\mathrm{NiCrFeCoMn}$ high-entropy alloy deformed at dynamic loadings.

Author Contributions: Conceptualization, B.W. and X.Z.; methodology, X.Y. and X.H.; validation, B.W. and Y.Z.; formal analysis, B.W., X.H., C.W. and X.Y.; investigation, B.W., X.H. and X.Y.; resources, B.W.; data curation, B.W., X.H., C.W. and X.Y.; writing-original draft preparation, B.W. and X.Y.; writing-review and editing, B.W. and Y.Z.; visualization, C.W.; supervision, B.W. and Y.Z..; project administration, B.W. and Y.Z.; funding acquisition, B.W. and Y.Z.

Funding: This research was funded by National Natural Science of China, grant number 51771231, and by State Key Laboratory of Powder Metallurgy, Central South University, Changsha, China, grant number 20181106.

Acknowledgments: Authors wish to express their most sincere gratitude to M.A. Meyers at University of California, San Diego, and Yong Liu at Central South University for their advice and help. Authors would like to express their sincere thanks to Yang Wang and Yu Wang at University of Science and Technology of China, and Xiang Zan at Hefei University of Technology for dynamic testing.

Conflicts of Interest: The authors declare no conflict of interest.

\section{References}

1. Yeh, J.W.; Chen, S.K.; Lin, S.J.; Gan, J.Y.; Chin, T.S.; Shun, T.T.; Tsai, C.H.; Chang, S.Y. Nanostructured high-entropy alloys with multiple principal elements: Novel alloy design concepts and outcomes. Adv. Eng. Mater. 2004, 6, 299-303. [CrossRef]

2. Yeh, J.W. Alloy design strategies and future trends in high-entropy alloys. JOM 2013, 65, 1759-1771. [CrossRef]

3. Zhang, Y.; Yan, X.; Liao, W.; Zhao, K. Effects of nitrogen content on the structure and mechanical properties of $\left(\mathrm{Al}_{0.5} \mathrm{CrFeNiTi}_{0.25}\right) \mathrm{Nx}$ high-entropy films by reactive sputtering. Entropy 2018, 20, 624. [CrossRef]

4. Salishchev, G.A.; Tikhonovsky, M.A.; Shaysultanov, D.G.; Stepanov, N.D.; Kuznetsov, A.V.; Kolodiy, I.V.; Tortikab, A.S.; Senkov, O.N. Effect of Mn and V on structure and mechanical properties of high-entropy alloys based on CoCrFeNi system. J. Alloy. Compd. 2014, 591, 11-21. [CrossRef]

5. Stepanov, N.; Tikhonovsky, M.; Yurchenko, N.; Zyabkin, D.; Klimova, M.; Zherebtsov, S.; Efimov, A.; Salishchev, G. Effect of cryo-deformation on structure and properties of CoCrFeNiMn high-entropy alloy. Intermetallics 2015, 59, 8-17. [CrossRef]

6. Schuh, B.; Mendez-Martin, F.; Völker, B.; George, E.P.; Clemens, H.; Pippan, R.; Hohenwarter, A. Mechanical properties, microstructure and thermal stability of a nanocrystalline CoCrFeMnNi high-entropy alloy after severe plastic deformation. Acta Mater. 2015, 96, 258-268. [CrossRef]

7. Otto, F.; Dlouhý, A.; Somsen, C.; Bei, H.; Eggeler, G.; George, E.P. The influences of temperature and microstructure on the tensile properties of a cocrfemnni high-entropy alloy. Acta Mater. 2013, 15, 5743-5755. [CrossRef]

8. Zhai, S.; Wang, W.; Xu, J.; Xu, S.; Zhang, Z.; Wang, Y. Effect of Co and Gd additions on microstructures and properties of FeSiBAlNi high entropy alloys. Entropy 2018, 20, 487. [CrossRef]

9. Feng, W.; Qi, Y.; Wang, S. Effects of short-range order on the magnetic and mechanical properties of FeCoNi(AlSi)x high entropy alloys. Metals 2017, 7, 482. [CrossRef]

10. Cicala, G.; Giordano, D.; Tosto, C.; Filippone, G.; Recca, A.; Blanco, I. Polylactide (PLA) filaments a biobased solution for additive manufacturing: Correlating rheology and thermomechanical properties with printing quality. Materials 2018, 7, 1191. [CrossRef] [PubMed]

11. Cicco, D.D.; Asaee, Z.; Taheri, F. Use of nanoparticles for enhancing the interlaminar properties of fiber-reinforced composites and adhesively bonded joints-A review. Nanomaterials 2017, 11, 360. [CrossRef] [PubMed] 
12. Laplanche, G.; Kostka, A.; Horst, O.M.; Eggeler, G.; George, E.P. Microstructure evolution and critical stress for twinning in the CrMnFeCoNi high-entropy alloy. Acta Mater. 2016, 118, 152-163. [CrossRef]

13. Kilmametov, A.; Kulagin, R.; Mazilkin, A.; Seils, S.; Boll, T.; Heilmaier, M.; Hahn, H. High-pressure torsion driven mechanical alloying of CoCrFeMnNi high entropy alloy. Scr. Mater. 2019, 158, 29-33. [CrossRef]

14. Wang, L.; Qiao, J.W.; Ma, S.G.; Jiao, Z.M.; Zhang, T.W.; Chen, G.; Zhao, D.; Zhang, Y.; Wang, Z.H. Mechanical response and deformation behavior of $\mathrm{Al}_{0.6} \mathrm{CoCrFeNi}$ high-entropy alloys upon dynamic loading. Mater. Sci. Eng. A 2018, 727, 208-213. [CrossRef]

15. Klimova, M.; Stepanov, N.; Shaysultanov, D.; Chernichenkoet, R.; Yurchenko, N.; Sanin, V.; Zherebtsov, S. Microstructure and mechanical properties evolution of the $\mathrm{Al}, \mathrm{C}$-containing CoCrFeNiMn-type high-entropy alloy during cold rolling. Materials 2018, 11, 53. [CrossRef] [PubMed]

16. Zherebtsov, S.; Stepanov, N.; Ivanisenko, Y.; Shaysultanov, D.; Yurchenko, N.; Klimova, M.; Salishchev, G. Evolution of microstructure and mechanical properties of a CoCrFeMnNi High-Entropy Alloy during high-pressure torsion at room and cryogenic temperatures. Metals 2018, 8, 123. [CrossRef]

17. He, J.Y.; Wang, H.; Huang, H.L.; Xu, X.D.; Chen, M.W.; Wu, Y.; Liu, X.J.; Nieh, T.G.; An, K.; Lu, Z.P. A precipitation-hardened high-entropy alloy with outstanding tensile properties. Acta Mater. 2016, 102, 187-196. [CrossRef]

18. Stepanov, N.D.; Shaysultanov, D.G.; Yurchenko, N.Y.; Zherebtsov, S.V.; Ladygin, A.N.; Salishchev, G.A.; Tikhonovsky, M.A. High temperature deformation behavior and dynamic recrystallization in CoCrFeNiMn high entropy alloy, Mater. Sci. Eng. A 2015, 636, 188-195. [CrossRef]

19. Ke, H.B.; Wen, P.; Peng, H.L.; Wang, W.H.; Greer, A.L. Homogeneous deformation of metallic glass at room temperature reveals large dilatation. Scr. Mater. 2011, 64, 966-969. [CrossRef]

20. Zhang, Y.; Liu, J.P.; Chen, S.Y.; Xie, X.; Liaw, P.K.; Dahmen, K.A.; Qiao, J.W.; Wang, Y.L. Serration and noise behaviors in materials. Prog. Mater. Sci. 2017, 90, 358-460. [CrossRef]

21. Wang, B.; Huang, X.; Fu, A.; Liu, Y.; Liu, B. Serration behavior and microstructure of high entropy alloy CoCrFeMnNi prepared by powder metallurgy. Mater. Sci. Eng. A 2018, 726, 37-44. [CrossRef]

22. Kumar, N.; Ying, Q.; Nie, X.; Mishra, R.S.; Tang, Z.; Liaw, P.K.; Brennan, R.E.; Doherty, K.J.; Cho, K.C. High strain-rate compressive deformation behavior of the $\mathrm{Al}_{0.1} \mathrm{CrFeCoNi}$ high entropy alloy. Mater. Des. 2015, 86, 598-602. [CrossRef]

23. Li, Z.; Zhao, S.; Diao, H.; Liaw, P.K.; Meyers, M.A. High-velocity deformation of $\mathrm{Al}_{0.3} \mathrm{CoCrFeNi}_{\text {high-entropy }}$ alloy: Remarkable resistance to shear failure. Sci. Rep. 2017, 7, 42742. [CrossRef] [PubMed]

24. Dirras, G.; Couque, H.; Lilensten, L.; Heczel, A.; Tingaud, D.; Couzinié, J.-P.; Perrière, L.; Gubicza, J.; Guillot, I. Mechanical behavior and microstructure of $\mathrm{Ti}_{20} \mathrm{Hf}_{20} \mathrm{Zr}_{20} \mathrm{Ta}_{20} \mathrm{Nb}_{20}$ high-entropy alloy loaded under quasi-static and dynamic compression conditions. Mater. Charact. 2016, 111, 106-113. [CrossRef]

25. He, J.; Wang, Q.; Zhang, H.; Dai, L.; Mukai, T.; Wu, Y.; Liu, X.; Wang, H.; Nieh, T.G.; Lu, Z. Dynamic deformation behavior of a face-centered cubic FeCoNiCrMn high-entropy alloy. Sci. Bull. 2018, 63, 362-368. [CrossRef]

26. Park, J.M.; Moon, J.; Bae, J.W.; Jang, M.J.; Park, J.; Lee, S.; Kim, H.S. Strain rate effects of dynamic compressive deformation on mechanical properties and microstructure of CoCrFeMnNi high-entropy alloy. Mater. Sci. Eng. A 2018, 719, 155-163. [CrossRef]

27. Wang, F.J.; Zhang, Y.; Chen, G.L. Atomic packing efficiency and phase transition in a high entropy alloy. J. Alloy. Compd. 2009, 478, 321-324. [CrossRef]

28. Zhou, Y.J.; Zhang, Y.; Wang, Y.L.; Chen, G.L. Microstructure and compressive properties of multicomponent $\mathrm{Al}_{X}(\mathrm{TiVCrMnFeCoNiCu})_{(100-X)}$ high-entropy alloys. Mater. Sci. Eng. A 2007, 454, 260-265. [CrossRef]

29. Zerilli, F.J.; Armstrong, R.W. Dislocation-mechanics-based constitutive relations for material dynamics calculations. Appl. Phys. 1987, 61, 1816-1825. [CrossRef]

30. Gali, A.; George, E.P. Tensile properties of high- and medium-entropy alloys. Intermetallics 2013, 39, 74-78. [CrossRef]

31. Fu, J.X.; Cao, C.M.; Tong, W.; Hao, Y.X.; Peng, L.M. The tensile properties and serrated flow behavior of a thermomechanically treated CoCrFeNiMn high-entropy alloy. Mater. Sci. Eng. A 2017, 690, 418-426. [CrossRef]

32. He, J.Y.; Zhu, C.; Zhou, D.Q.; Liu, W.H.; Nieh, T.G.; Lu, Z.P. Steady state flow of the FeCoNiCrMn high entropy alloy at elevated temperatures. Intermetallics 2014, 55, 9-14. [CrossRef] 
33. Moon, J.; Hong, S.I.; Bae, J.W.; Jang, M.J.; Yim, D.; Kim, H.S. On the strain rate-dependent deformation mechanism of CoCrFeMnNi high entropy alloy at liquid nitrogen temperature. Mater. Res. Lett. 2017, 5, 472-477. [CrossRef]

34. Antonaglia, J.; Xie, X.; Tang, Z.; Tsai, C.W.; Qiao, J.W.; Zhang, Y.; Laktionova, M.O.; Tabachnikova, E.D.; Yeh, J.W.; Senkov, O.N.; et al. Temperature effects on deformation and serration behavior of high-entropy alloys (HEAs). JOM 2014, 66, 2002-2008. [CrossRef] 